\title{
Differential role of entorhinal and hippocampal nerve growth factor in short- and long-term memory modulation
}

R. Walz ${ }^{4}$, R. Roesler ${ }^{3}$, A. Reinke ${ }^{1}$, M.R. Martins ${ }^{1}$, J. Quevedo 1,2 and I. Izquierdo ${ }^{2}$

\author{
${ }^{1}$ Laboratório de Neurotoxicologia, Universidade do Extremo Sul Catarinense, \\ Criciúma, SC, Brasil \\ ${ }^{2}$ Centro de Memória, Departamento de Bioquímica, and \\ ${ }^{3}$ Laboratório de Neurofarmacologia Pré-Clínica, Departamento de Farmacologia, \\ Instituto de Ciências Básicas da Saúde, Universidade Federal do Rio Grande do Sul, \\ Porto Alegre, RS, Brasil \\ ${ }^{4}$ Departamento de Medicina, Universidade do Vale do Itajaí, Itajaí, SC, Brasil
}

\section{Correspondence}

J. Quevedo

Laboratório de Neurotoxicologia

Universidade do Extremo Sul

Catarinense

88806-000 Criciúma, SC

Brasil

Fax: +55-48431-2750

E-mail: quevedo1@terra.com.br

Received April 14, 2004 Accepted September 20, 2004

\begin{abstract}
We studied the effects of infusion of nerve growth factor (NGF) into the hippocampus and entorhinal cortex of male Wistar rats (250-300 g, $\mathrm{N}=11-13$ per group) on inhibitory avoidance retention. In order to evaluate the modulation of entorhinal and hippocampal NGF in shortand long-term memory, animals were implanted with cannulae in the CA1 area of the dorsal hippocampus or entorhinal cortex and trained in one-trial step-down inhibitory avoidance (foot shock, $0.4 \mathrm{~mA}$ ). Retention tests were carried out $1.5 \mathrm{~h}$ or $24 \mathrm{~h}$ after training to measure short- and long-term memory, respectively. Immediately after training, rats received $5 \mu \mathrm{l} \mathrm{NGF}(0.05,0.5$ or $5.0 \mathrm{ng})$ or saline per side into the CA1 area and entorhinal cortex. The correct position of the cannulae was confirmed by histological analysis. The highest dose of NGF (5.0 ng) into the hippocampus blocked short-term memory ( $\mathrm{P}<$ $0.05)$, whereas the doses of $0.5(\mathrm{P}<0.05)$ and $5.0 \mathrm{ng}(\mathrm{P}<0.01) \mathrm{NGF}$ enhanced long-term memory. NGF administration into the entorhinal cortex improved long-term memory at the dose of $5.0 \mathrm{ng}(\mathrm{P}<0.05)$ and did not alter short-term memory. Taken as a whole, our results suggest a differential modulation by entorhinal and hippocampal NGF of short- and long-term memory.
\end{abstract}

Neurotrophins, traditionally viewed as trophic proteins for neuronal survival and differentiation, have recently emerged as a new class of neuromodulators for synaptic transmission and plasticity, particularly in the central nervous system (1).

Nerve growth factor (NGF) is the prototype member of the neurotrophin family. It is
Key words

- Nerve growth factor

- Hippocampus

- Entorhinal cortex

- Short- and long-term memory

- Inhibitory avoidance

- Rat secreted by hippocampal neurons in culture and in slices (2) and, like other neurotrophins, it delivers its message inside the cell via interaction with cell surface receptors (3). The specific binding of NGF to neurotrophin receptors coupled to tyrosine kinase A leads to dimerization and autophosphorylation of the kinase molecule. The tyrosine- 
phosphorylate receptor ultimately propagates the NGF signal to the Ras mitogen-activated protein kinase (MAPK) pathway (3).

Continuous intracerebroventricular NGF infusion enhances retention of passive avoidance learning in developing mice (4), and a similar infusion of anti-NGF antibody over four weeks impairs water maze performance (5). Bergado and colleagues (6) reported that chronic intracerebroventricular NGF administration to old rats improves long-term potentiation in the dentate gyrus (6). A similar NGF infusion has a beneficial effect on performance in the Morris water maze after fluid-percussion brain injury, which is accompanied by a sparing of cholinergic septal neurons (7). Additionally, NGF can be retrogradely transported by cholinergic neurons in the basal forebrain, preventing death of axotomized septal neurons, as well as reversing the atrophy of these neurons observed in aging rats (8).

Walz et al. (9) reported that infusion of NGF into the CA1 region of hippocampus at doses of 0.5 and $5.0 \mathrm{ng}$ per side at 0 and 120 min after inhibitory avoidance enhanced long-term memory. They also described a significant enhancement of MAPK activity in hippocampal slices after NGF infusion (5.0 ng).

The entorhinal cortex is an essential component of the medial temporal lobe in memory consolidation (10). The entorhinal cortex exerts a potent influence on the hippocampus because of its extensive monosynaptic projections to this area (11).

Shimode and colleagues (12) demonstrated that continuous intracerebroventricular infusions of NGF ameliorated hippocampal cholinergic deficits and learning impairment following entorhinal cortex lesions.

To address the involvement of the entorhinal cortex and hippocampal NGF in shortand long-term memory formation, we studied the effects of infusion of NGF into the CA1 region of the hippocampus and entorhinal cortex on inhibitory avoidance reten- tion in rats.

The animals were submitted to a single training session $(0.4 \mathrm{~mA}$ foot shock over a period of $2 \mathrm{~s}$ ). In order to evaluate short-term memory and long-term memory, test sessions were performed 1, 5 and $24 \mathrm{~h}$ after training. Male Wistar rats were implanted bilaterally under thionembutal anesthesia (30 mg/kg, intraperitoneally) with $9.0-\mathrm{mm}$ guide cannulae aimed $1.0 \mathrm{~mm}$ above the dorsal CA1 region of the hippocampus and entorhinal cortex. The stereotaxic coordinates used were Paxinos and Watson (13) atlas: A $-4.2, \mathrm{~L} \pm 3.0, \mathrm{~V}-2.3$ for $\mathrm{CA} 1$ and $\mathrm{A}-0.67, \mathrm{~L}$ $\pm 3.0, \mathrm{~V}-0.48$ for the entorhinal cortex. The infusions were performed through a tightfitting inner probe placed within the guide cannulae immediately after the training session. Each group $(\mathrm{N}=11-13)$ received a 0.5 $\mu \mathrm{l}$ infusion of NGF bilaterally at the dose of 0.5 or $5.0 \mathrm{ng}$ dissolved in saline, $\mathrm{pH} 7.4$ (concentrations of the NGF solution were 0.1 or $10 \mathrm{ng} / \mu \mathrm{l}$ ) or saline only. One or two days after the end of the behavioral procedures the animals were sacrificed by decapitation. Histological analysis of cannula placement was performed and only behavioral results for animals with correct cannula placement (i.e., within $1 \mathrm{~mm}^{2}$ of the intended sites) were considered. All experimental procedures involving animals were performed in accordance with the NIH Guide for the Care and Use of Laboratory Animals and the recommendations of the Brazilian Society for Neuroscience and Behavior (SBNeC).

The effects of NGF infusion into the CA1 region of the hippocampus on short- and long-term memory are shown in Figure 1A and $\mathrm{B}$, respectively. NGF impaired shortterm memory at the dose of $5.0 \mathrm{ng}$. In contrast, NGF improved long-term memory at all doses studied ( $0.5 \mathrm{ng}, \mathrm{P}<0.05 ; 5.0 \mathrm{ng}, \mathrm{P}$ $<0.01)$. Data for the various groups were compared by the Mann-Whitney U-test. All groups, except the amnestic ones, showed significant training-test differences $(\mathrm{P}<0.01$, Wilcoxon test). 
The effects of NGF administration into the entorhinal cortex on short- and long-term memory are shown in Figure 2A and B, respectively. No differences in short-term memory were observed among groups. However, NGF infusion enhanced long-term memory at the dose of $5.0 \mathrm{ng}(\mathrm{P}<0.05)$. Data for the various groups were compared by the Mann-Whitney U-test. All groups showed significant training-test differences $(\mathrm{P}<0.01$, Wilcoxon test).

Our findings demonstrated an improvement in long-term memory in rats that received a single bilateral infusion of NGF ( 0.5 or $5.0 \mathrm{ng}$ ) into the CA1 region of the hippocampus immediately after training. This enhancement in long-term memory agrees with our previous findings (9) in a study that showed a significant activation of MAPK 30 min after NGF infusion into the CA1, which persisted for $180 \mathrm{~min}$.

In previous studies, we have shown that the injection of the MAPK cascade inhibitor into the CA1 impairs long-term memory at $180 \mathrm{~min}$, but not at 0,90 or $360 \mathrm{~min}$ after training (14). Regarding the contextual fear conditioning paradigm, MAPK activation in the hippocampus is crucial at about $120 \mathrm{~min}$ after conditioning (15). Therefore, the enhancement in long-term memory by NGF infusion immediately after training can be due, at list in part, to an effect on the activation of the Ras-MAPK cascade after inhibitory avoidance training. The lack of effect of $0.5 \mathrm{ng} / 0.5 \mu 1$ infusion of NGF on long-term memory also agrees with previous studies $(9,16)$. In addition, NGF activates MAPK to stimulate phosphorylation of cAMP response element-binding protein at serine 133 in $\mathrm{PC} 12$ cells (17). In contrast, NGF administration at the dose of $5.0 \mathrm{ng}$ impaired short-term memory. This effect can be related to possible apoptotic activity of NGF and/or its proNGF precursor form. Moreover, it is not known whether proNGF has apoptotic or neurotrophic activity.

The role of the entorhinal cortex in memory formation is well known $(10,11,14)$. In the present study, we showed that infusion of NGF into the entorhinal cortex enhanced long-term memory only at the higher
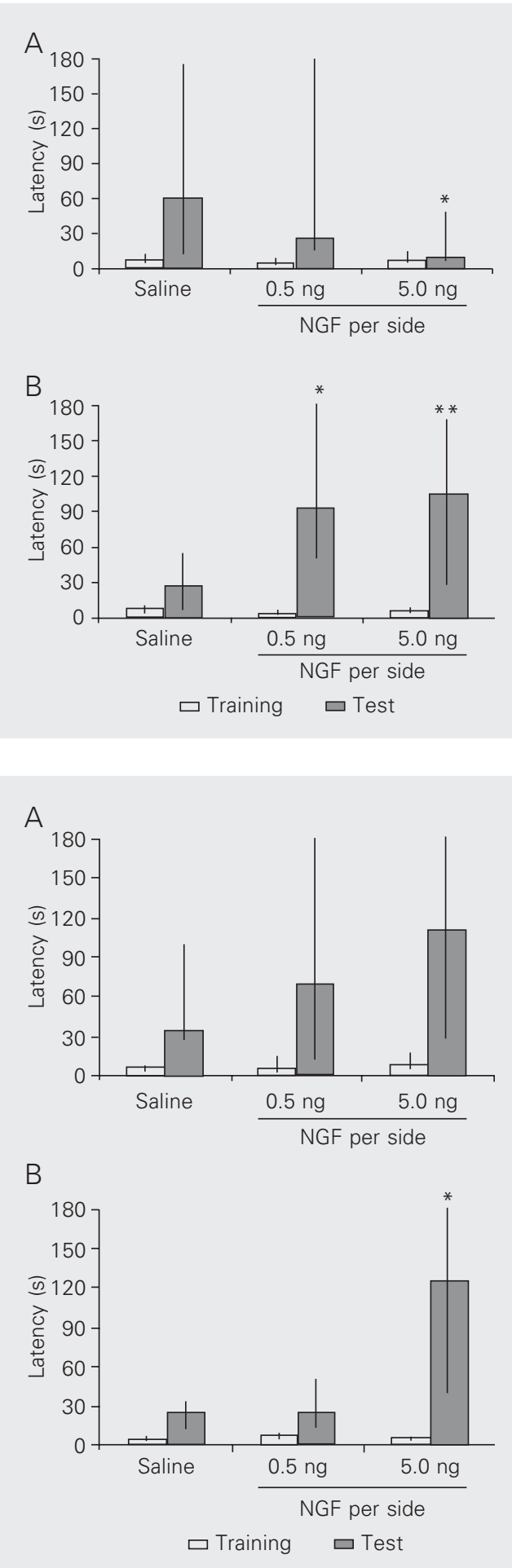

Figure 1. Effects of intrahippocampal (CA1) infusion of nerve growth factor (NGF) on short(A) and long-term (B) memory in a one-trial step-down inhibitory avoidance task. Data are reported as median (interquartile range) latency (in seconds) in training and test sessions. $\mathrm{N}=$ $11-13$ per group. ${ }^{*} \mathrm{P}<0.05$ and ${ }^{*} \mathrm{P}<0.01$ compared with the vehicle-treated group (MannWhitney U-test). All groups, except the amnestic ones, showed significant training-test differences $(P<0.01$, Wilcoxon test).

Figure 2. Effects of nerve growth factor (NGF) infusion into the entorhinal cortex on short- (A) and long-term (B) memory in a one-trial step-down inhibitory avoidance task. Data are reported as median (interquartile range) latency (in seconds) in training and test sessions. $\mathrm{N}=11-13$ per group. ${ }^{*} \mathrm{P}<$ 0.05 compared with the vehicletreated group (Mann-Whitney U-test). All groups showed significant training-test differences $(P<0.01$, Wilcoxon test). 
dose studied (5.0 ng) but did not alter shortterm memory.

Recent studies from our laboratory have shown that, for the one-trial inhibitory avoidance task, the short-term memory system operates separately from long-term memory formation in the hippocampus and related brain areas. Thus, several pharmacological treatments block short-term memory while leaving long-term memory intact when administered into the hippocampus, entorhinal cortex, parietal cortex, and prefrontal cortex $(18-20)$. In the present study, we demonstrated that NGF modulates short- and longterm memory in a different manner in both the hippocampus and entorhinal cortex.

\section{References}

1. Lu B (2003). Pro-region of neurotrophin: role in synaptic modulation. Neuron, 39: 735-738.

2. Blochl A \& Thoenen $H$ (1995). Characterization of nerve growth factor (NGF) release from hippocampal neurons: evidence for a constitutive and an unconventional sodium-dependent regulated pathway. European Journal of Neuroscience, 7: 1220-1228.

3. Segal RA \& Greenberg ME (1996). Intracellular signaling pathways activated by neurotrophic factors. Annual Review of Neuroscience, 19: $463-489$

4. Ricceri L, Alleva E, Chiarotti F \& Calamandrei G (1996). Nerve growth factor affects passive avoidance learning and retention in developing mice. Brain Research Bulletin, 39: 219-226.

5. Nabeshima T, Ogawa S, Yamada K, Ishimaru H, Fuji K, Kameyama T, Fukuta T, Takeuchi R \& Hayashi K (1991). Memory impairment and morphological changes in rats after continuous infusion of active fragment of anti-nerve growth factor-antibody. Research Communications in Chemical Pathology and Pharmacology, 74: 141-152.

6. Bergado JA, Gomez-Soria AA, Cruz R \& Fernandez Cl (1998). Nerve growth factor improves evoked potentials and long-term potentiation in the dentate gyrus of presenile rats. European Journal of Pharmacology, 345: 181-184.

7. Sinson G, Perri BR, Trojanowski JQ, Flamm ES \& Mclntosh TK (1997). Improvement of cognitive deficits and decreased cholinergic neuronal cell loss and apoptotic cell death following neurotrophin infusion after experimental traumatic brain injury. Journal of Neurosurgery, 86: 511-518.

8. Lewin GR \& Barde YA (1996). Physiology of the neurotrophins. Annual Review of Neuroscience, 19: 289-317.

9. Walz R, Lenz G, Roesler R, Vianna MM, Martins V, Brentani R, Rodnight R \& Izquierdo I (2000). Time-dependent enhancement of inhibitory avoidance retention and MAPK activation by post-training infusion of nerve growth factor into CA1 region of hippocampus of adult rats. European Journal of Neuroscience, 12: 2185-2189.

10. Izquierdo I \& Medina JH (1997). Memory formation: the sequence of biochemical events in the hippocampus and its connection to activity in other brain structures. Neurobiology of Learning and Memory, 68: 285-316.
11. Yaniv D, Vouimba RM, Diamond DM \& Richter-Levin G (2003) Simultaneous induction of long-term potentiation in the hippocampus and the amygdala by entorhinal cortex activation: mechanistic and temporal profiles. Neuroscience, 120: 1125-1135.

12. Shimode H, Ueki A \& Morita $Y$ (2003). Nerve growth factor attenuates hippocampal cholinergic deficits and operant learning impairment in rats with entorhinal cortex lesions. Behavioural Pharmacology, 14: 179-190.

13. Paxinos G \& Watson C (1986). The Rat Brain in Stereotaxic Coordinates. Academic Press, San Diego, CA, USA.

14. Walz R, Roesler R, Quevedo J, Madruga M, Rodrigues C, Godfried C, Medina JH \& Izquierdo I (1999). Time-dependent impairment of inhibitory avoidance retention by mitogen activated protein kinase inhibitor infusion into the cortical and limbic structures. Neurobiology of Learning and Memory, 73: 11-20.

15. Atkins CM, Selcher JJ, Petraitis JJ, Trzaskos JM \& Sweatt JD (1998). The MAPK cascade is required for mammalian associative learning. Nature Neuroscience, 1: 602-609.

16. Kang H \& Schuman EM (1995). Long-lasting neurotrophin-induced enhancement of synaptic transmission in the adult hippocampus. Science, 267: 1658-1662.

17. Xing J, Kornhauser JM, Xia Z, Thiele EA \& Greenberg ME (1998). Nerve growth factor activates extracellular signal-regulated kinase and p38 mitogen-activated protein kinase pathways to stimulate CREB serine 133 phosphorylation. Molecular and Cellular Biology, 18: $1946-1955$

18. Izquierdo I, Barros DM, Mello e Souza T, de Souza MM, Izquierdo LA \& Medina JH (1998). Mechanisms for memory types differ. Nature, 393: 635-636.

19. Izquierdo LA, Barros DM, Vianna MR, Coitinho A, deDavis e Silva T, Choi H, Moletta B, Medina JH \& Izquierdo I (2002). Molecular pharmacological dissection of short- and long-term memory. Cellular and Molecular Neurobiology, 22: 269-287.

20. Vianna MR, Izquierdo LA, Barros DM, Ardenghi $P$, Pereira $P$, Rodrigues C, Moletta B, Medina JH \& Izquierdo I (2000). Differential role of hippocampal CAMP-dependent protein kinase in short- and longterm memory. Neurochemical Research, 25: 621-626. 